Cite this: J. Mater. Chem. B, 2014, 2, 3886

Received 31st January 2014

Accepted 25th April 2014

DOI: $10.1039 / c 4 t b 00173 g$

www.rsc.org/MaterialsB

\title{
Enhancing in vitro biocompatibility and corrosion protection of organic-inorganic hybrid sol-gel films with nanocrystalline hydroxyapatite
}

\begin{abstract}
A. A. El hadad, ae V. Barranco, ${ }^{\text {b }}$ A. Jiménez-Morales, ${ }^{c}$ E. Peón, ${ }^{d}$ G. J. Hickman, ${ }^{e}$ C. C. Perry ${ }^{\star e}$ and J. C. Galván*a

Application of novel organic-inorganic hybrid sol-gel coatings containing dispersed hydroxyapatite (HAp) particles improves the biocompatibility, normal human osteoblast (NHOst) response in terms of osteoblast viability and adhesion of a Ti6Al4V alloy routinely used in medical implants. The incorporation of HAp particles additionally results in more effective barrier proprieties and improved corrosion protection of the Ti6Al4V alloy through higher degree of cross-linking in the organopolysiloxane matrix and enhanced film thickness.
\end{abstract}

\section{Introduction}

Ti6Al4V alloys are widely used in the reconstruction of degraded human tissue in dental and orthopaedic fields, where the materials surface properties are considered to be a very important factor in the improvement of such implants. ${ }^{1} \mathrm{~A}$ range of materials have been used to modify metallic implant surfaces to improve osteointegration and bone growth. ${ }^{2}$

Inorganic sol-gel coatings are an alternative to conventional organic coatings; they have excellent abrasion resistance and high density but they tend to be brittle and require high processing temperatures. ${ }^{2,3}$ In contrast organic-inorganic hybrids prepared by the sol-gel route are potentially of great interest as they combine characteristics of both organic and inorganic materials. ${ }^{4}$ Organic-inorganic hybrids appear as a creative alternative for obtaining new materials with unusual properties, ${ }^{5}$ the organic groups help the hybrid films obtain flexibility, and thus, are less prone to cracking during thermal treatment.

Organic-inorganic hybrid coatings by a sol-gel process additionally offer many advantages over other methods such as plasma spraying, electrophoresis, ${ }^{6}$ etc. These include high purity reactants and resulting products; low temperature processing, good adhesion with minimal cracking and easy application to almost any kind of substrate. Corrosion resistance of coatings

${ }^{a}$ Centro Nacional de Investigaciones Metalúrgicas (CSIC), Madrid, Spain. E-mail: jcgalvan@cenim.csic.es

${ }^{b}$ Instituto de Ciencia de Materiales de Madrid (CSIC), Madrid, Spain

'Universidad Carlos III de Madrid, Departamento de Ciencia e Ingeniería de Materiales e Ingeniería Química, Leganés, Spain

${ }^{d}$ Centro de Biomateriales, Universidad de La Habana, Cuba

Interdisciplinary Biomedical Research Centre, School of Science and Technology, Nottingham Trent University, Clifton Lane, Nottingham NG11 8NS, UK. E-mail: Carole.Perry@ntu.ac.uk depend on the ability to act as physical barrier. Plasma spray and biomimetic coatings are vulnerable to cracking in the film, ${ }^{6}$ which should be avoided. Organic-inorganic films are normally obtained by dip-coating where a stable thin film is obtained via immersion of a metal substrate in an alcohol-water based silane solution. Silane films are expected to act as a barrier against diffusion of corrosive species from the metal surface. ${ }^{7}$ Silanes contain hydrolysable alkoxy groups which are converted to hydrophilic silanol groups ( $\mathrm{Si}-\mathrm{OH})$. When these groups come into contact with hydroxyl-covered metallic surfaces (Me-OH), upon curing, a condensation reaction takes place forming metallosiloxane bonds (Me-O-Si) adhering the silane to the metallic surface. ${ }^{8}$ The excess $\mathrm{Si}-\mathrm{OH}$ groups in the adsorbed layer form a siloxane network ( $\mathrm{Si}-\mathrm{O}-\mathrm{Si}$ ), which impedes the penetration of corrosive agents such as water, oxygen, and chloride ions. The corrosion resistance of organic-inorganic hybrid coatings prepared using sol-gels is based on physical barrier properties and a homogenous defect-free material is required. However, in both hydrolysis and condensation reactions, low molecular weight by-products such as alcohol are produced. ${ }^{9}$ Effective drying of hybrid films requires that by-products and water escape as the gel solidifies. Due to the evaporation of alcohol and water, small pores develop which provide paths for electrolyte to diffuse through the coating and corrode the metal substrate. ${ }^{\mathbf{1 0}}$ The combination of a sol-gel organic-inorganic hybrid film with the addition of HAp particles may be an efficient method to increase the barrier properties and bioactivity of coating films. HAp particles may bond with bone and may enhance the corrosion protection ability of the sol-gel coatings, either by increasing the coating thickness or by having a pore blocking effect. Such a coating may also improve osteoblast viability by acting as a barrier to the release of metal ions from the alloy to the surrounding cells.

This study assesses the influence of a dispersion of inorganic hydroxyapatite (HAp) powders on organic-inorganic hybrid 
coatings developed to improve osteointegration as well as metal alloy corrosion protection. The effect of HAp incorporation, on the structure, composition and morphology of the prepared hybrid films, in addition to the in vitro bioactivity of these coatings has been assessed.

\section{Experimental}

\section{MAPTMS/TMOS/HAp hybrid sol preparation and deposition on Ti6Al4V substrates}

Mixtures of $\gamma$-methacryloxypropyltrimethoxysilane $98 \%$ (MAPTMS) and tetramethoxysilane 98\% (TMOS) from Aldrich were used as organopolysiloxane matric precursors at a molar ratio of $4: 1$. Ethanol (99.8\%) and $\mathrm{ddH}_{2} \mathrm{O}$ were used as solvents with MAPTMS hydrolysed with $\mathrm{H}_{2} \mathrm{O}$ through stirring, mixed with TMOS vigorously and stirred (700 rpm for $4 \mathrm{~h}$ ). The molar ratio of silane-water-ethanol was $1: 3: 3$. Hybrid coatings were modified with dispersions of nanocrystalline ( $40 \mathrm{~nm}$ domain crystallites previously determined by the Scherer equation) hydroxyapatite (HAp) particles previously prepared in our laboratory by a sol-gel method. ${ }^{2}$ HAp powder with an average particle size $<20 \mu \mathrm{m}$ was dispersed at a concentration of $0,0.5,1$ and $1.5 \mathrm{wt} \%$, relative to the silane sol, such wt\% were selected to avoid HAp agglomerates and avoid mechanical defects noted for higher additions. ${ }^{11}$ Triton X-100 was used as a dispersant with mechanical stirring and ultrasonic agitation to break down any agglomerates.

Ti6Al4V disks ( $2 \mathrm{~cm}$ diameter $\times 0.4 \mathrm{~cm}$ thickness) were used. The surface was ground using grit sand papers starting from 320 to 2000 grit size to achieve a uniform surface. Specimens were rinsed with $\mathrm{dd}_{2} \mathrm{O}$ and ultrasonically cleaned in ethanol for 10 min for degreasing and to remove contamination on the surfaces then dried in air. Hybrid coatings were deposited at ambient temperature by immersion of Ti6Al4V alloys in freshly prepared MAPTMS/TMOS sol containing HAp particles followed by withdrawal at $9 \mathrm{~cm} \mathrm{~min}^{-1}$, with a holding time of $1 \mathrm{~min}$ using a dip-coater. Coated surfaces were cured for $2 \mathrm{~h}$ at a temperature of $120{ }^{\circ} \mathrm{C}$. Curing temperature was selected to avoid decomposition of the organic component in the hybrid and to act as the final step in obtaining the $\mathrm{Si}-\mathrm{O}-\mathrm{Si}$ network and $\mathrm{Me}-\mathrm{O}-\mathrm{Si}$ bonds between the metal surface and deposited film.

\section{Characterization of prepared Ti6Al4V substrates}

Thermal characterization of the hybrid samples was performed by thermogravimetric analysis (TGA) using a SETARAM DTA-TG SETSYS Evolution-1750 system, with $\alpha-\mathrm{Al}_{2} \mathrm{O}_{3}$ reference. $5 \mathrm{mg}$ of each xerogel were analysed. The sample and reference material were heated in air from room temperature to $900{ }^{\circ} \mathrm{C}$ at a rate of $20{ }^{\circ} \mathrm{C} \mathrm{min}^{-1}$. Structural features and functional groups in cured hybrid coatings were characterized by attenuated total reflectance-Fourier transform infrared spectroscopy (ATR-FTIR) using a Nicolet Magna IR 550 infrared spectrophotometer. Spectra were recorded between 400 and $4000 \mathrm{~cm}^{-1}$ with a resolution of $4 \mathrm{~cm}^{-1}$ at room temperature. For each measurement 8 scans were collected.

${ }^{29} \mathrm{Si},{ }^{13} \mathrm{C}$ and ${ }^{31} \mathrm{P}$ MAS NMR spectra of the solid samples were recorded at 79.49, 100.62 and $161.97 \mathrm{MHz}$ respectively, using a
Bruker AVANCE-400 spectrometer. The external magnetic field was 9.4 Tesla. All measurements were carried out at $20^{\circ} \mathrm{C}$ and the samples were spun at the magic angle $\left(54^{\circ} 44^{\prime}\right.$ with respect to the magnetic field) at a rate of $10 \mathrm{kHz}$. The ${ }^{29} \mathrm{Si}$ and ${ }^{31} \mathrm{P}$ spectra were obtained with single pulse sequences after excitation with a $\pi / 2$ pulse length of $5 \mu \mathrm{s}$, and intervals between successive accumulations (recycle delay) of $10 \mathrm{~s}$ for both signals. CPMAS (cross polarization and proton decoupling) NMR spectra were obtained for ${ }^{13} \mathrm{C}$ with a contact time of $1 \mathrm{~ms}$ and a recycle delay of $10 \mathrm{~s}$. The number of scans was 400 in the case of ${ }^{29} \mathrm{Si}$ and ${ }^{31} \mathrm{P}$ and 600 for ${ }^{13} \mathrm{C}$. The ${ }^{29} \mathrm{Si}$ and ${ }^{13} \mathrm{C}$ chemical shift values are given relative to $\left(\mathrm{CH}_{3}\right)_{4} \mathrm{Si}$. The ${ }^{31} \mathrm{P}$ and chemical shift values are given relative to $85 \% \mathrm{H}_{3} \mathrm{PO}_{4}$ aqueous solution. Deconvolution of NMR spectra into individual Gaussian components was carried out with the WINFIT program.

Wettability of the coated Ti6Al4V alloys was determined by measuring the contact angle of $2 \mu \mathrm{L}$ drops of distilled water (polar fluid) on the surface of the specimen; three drops per sample were immediately analysed. The sessile drop method was used for contact angle measurements using a Video-based Optical Contact Angle Measuring Instrument OCA-15 Plus controlled by a SCA20 software module from Data Physics supplied by Neurtek SA (Spain). This was repeated three times to allow a mean and standard deviation to be calculated.

Coating thickness was measured on half coated samples with a stylus profilometer (Form Talysurf 50 Model, TaylorHobson, Leicester, UK). Linear scans of $1 \mathrm{~mm}$ were measured across the step between the uncoated and coated surface. Three different areas of each film were studied and coating thickness expressed as a mean value \pm standard deviation.

\section{Morphology and composition of prepared Ti6Al4V substrates}

The morphology and composition of the prepared films was assessed using a Phillips LX30 environmental scanning electron microscope (SEM) with field emission gun operating between 5-15 kV acceleration voltage, energy dispersive X-ray analysis (EDXa) was used for elemental analysis and mapping, samples were coated with Pt to avoid charging. A JEOL 6500F SEM operating at $15 \mathrm{kV}$ acceleration voltage with EDXa was used to assess samples after biomineralisation where samples were coated with a thin layer of carbon.

Film roughness was evaluated with an Optical Imaging Profiler Sensofar PL $\mu 2300$ operating in confocal mode. Measurements were realized by using a confocal objective EPI $20 \times$ at a working distance of 4.5 with an numerical aperture of 0.45 , which results in a spatial sampling of $0.8 \mu \mathrm{m}$ and a rms resolution of $<20 \mathrm{~nm}$. Three different areas were selected on each sample. On each area, eight roughness measurements were performed to obtain the $R_{\mathrm{a}}$ parameter, among others. Concretely, $R_{\mathrm{a}}$ was obtained from $80 \mu \mathrm{m}$ line scans. $R_{\mathrm{a}}$ values are mean values obtained as result of 24 measurements for each sample.

\section{Biomineralisation, protein adsorption, cell viability/ cytotoxicity assays and cytoskeletal observations by immunofluorescence}

In vitro bioactivity was assessed for the $0 \mathrm{wt} \%$ and $1.5 \mathrm{wt} \%$ HAp in a simulated body fluid (SBF) solution as described by Kokubo 
et al. ${ }^{12}$ prepared by dissolving $\mathrm{NaCl}, \mathrm{KCl}, \mathrm{NaHCO}_{3}, \mathrm{~K}_{2} \mathrm{HPO}_{4}$. $3 \mathrm{H}_{2} \mathrm{O}, \mathrm{MgCl}_{2} \cdot 6 \mathrm{H}_{2} \mathrm{O}, \mathrm{CaCl}_{2}$ and $\mathrm{Na}_{2} \mathrm{SO}_{4}$ in $\mathrm{ddH}_{2} \mathrm{O}$. The solution was buffered at $\mathrm{pH} 7.4 \mathrm{using}$ tris(hydroxymethyl)aminomethane $/ \mathrm{HCl}$ and filtered $(0.22 \mu \mathrm{m}$ Millipore filters) to avoid bacterial contamination. SBF treatment was carried out at $37{ }^{\circ} \mathrm{C}$, using a sealed polyethylene container under continuous orbital stirring $(600 \mathrm{rpm})$ in an Ecotron HT incubator. After 15 days immersion specimens were removed from solution, rinsed with $\mathrm{ddH}_{2} \mathrm{O}$ and dried at room temperature before analysis by SEM and EDXa.

Protein adsorption was studied using fibrinogen as a representative protein. Samples were rinsed with phosphate-buffered saline (PBS), pH 7.4 to rehydrate the surface and transferred into six well plates (Sarstedt Inc, Germany) after which $4 \mathrm{~mL}$ of $1 \mathrm{mg} \mathrm{mL} \mathrm{m}^{-1}$ fibrinogen solution in PBS was pipetted onto each surface (50 mM Tris/HCl, pH 7.4, $100 \mathrm{mM} \mathrm{NaCl,} 5 \mathrm{mM} \mathrm{MgCl}_{2}$ ). Adsorption was allowed to proceed in an incubator for $1 \mathrm{~h}$ at $37{ }^{\circ} \mathrm{C}$. Samples were thoroughly rinsed with $\mathrm{PBS}$ and $\mathrm{dd}_{2} \mathrm{O}$ three times to remove unbound protein and salt residues. Adsorbed protein was determined by measuring the protein remaining in solution by the Bradford method, absorbance was measured using a well-plate reader at a wavelength of $595 \mathrm{~nm}$. Three samples of each hybrid powder were studied with protein adsorption expressed as a mean value \pm standard deviation.

In vitro studies were performed on coated and untreated Ti6Al4V substrates using normal human osteoblasts (NHOst cells, Lonza, UK). NHOst were cultured at $37{ }^{\circ} \mathrm{C}$ with $5 \% \mathrm{CO}_{2}$ in osteoblast basal medium (Lonza, UK) supplemented with $10 \%$ foetal calf serum, $1 \%$ gentamycin sulphate and 1\% ascorbic acid. Cultures were initiated and maintained as per the supplier's instructions. Cell viability on the different substrates was assessed in the manner described by Repetto et al. ${ }^{13}$ using the Neutral-red assay. Coated Ti6Al4V disks of $2 \mathrm{~cm}$ diameter and $0.4 \mathrm{~cm}$ thickness were sterilized by exposure to methanol. Discs were placed in six well plates (Sarstedt Inc., UK) and 2500 cells per $\mathrm{cm}^{2}$ seeded to each substrate. Discs were incubated under normal conditions with refreshment of the media after three days. After seven days the medium was replaced with RPMI1640 medium (Lonza, UK) containing 0.01\% neutral red dye (Sigma-Aldrich, UK) and the plates incubated for $2 \mathrm{~h}$ under normal conditions. Discs were rinsed with PBS and then an equal volume of de-stain solution ( $1 \%$ glacial acetic acid, 50\% ethanol). Plates were shaken for $20 \mathrm{~min}$ and absorbance at $540 \mathrm{~nm}$ was read by a micro-plate reader (Tecan, Switzerland). The experiment was performed four times in triplicate and disks without cells were used to correct for dye adsorbed to disks. Cell viability/cytotoxicity data was normalised and assessed using GraphPad Prism v.5, using a one way ANOVA, and Tukey's multiple pairwise comparison. A confidence level was 0.05 and the assumption of normality was assessed in each case.

The osteoblast cytoskeleton (f-actin and focal adhesion sites) was visualized by staining after seven days of culture under normal conditions, $0.9 \mathrm{~mm}$ disks seeded with 2500 cells per $\mathrm{cm}^{2}$. One unit of Alexa Fluor 568 phalloidin (Invitrogen, UK) was used to stain f-actin. Monoclonal mouse anti-human vinculin (clone hVIN-1) IgG1 (Sigma-Aldrich, UK) at a concentration of
1 : 1000 with Alexa Fluor 488 conjugated goat anti-mouse IgG (Invitrogen, UK) secondary at a concentration of $1: 1500$ was used to visualize focal adhesion sites. Vectashield mounting solution (Vector Laboratories, USA) containing 4,6-diamidino-2phenylindole was used to stain cell nuclei and applied before imaging with an Olympus DP71 fluorescence microscope.

\section{Corrosion protection behaviour of the coated Ti6Al4V substrates}

Corrosion protection behaviour of the organic-inorganic hybrid/Ti6Al4V system was evaluated in an electrochemical cell maintained at $37^{\circ} \mathrm{C}$ filled with Kokubo's solution (as described above) by electrochemical impedance spectroscopy (EIS). A potentiostat/galvanostat AutoLab EcoChemie PGSTAT30 (Eco Chemie, Utrecht, the Netherlands) equipped with a FRA2 frequency response analyser module was used. A conventional three electrode setup was applied. The working electrode was the investigated sample with an area of $2.14 \mathrm{~cm}^{2}$. The reference and the counter-electrode were a saturated calomel electrode (SCE) and a large size graphite sheet, respectively. The EIS measurements were made at the open circuit potential (OCP). Logarithmic frequency scans were carried out by applying sinusoidal wave perturbations of $\pm 10 \mathrm{mV}$ in amplitude, in the range $10^{5}$ to $10^{-3} \mathrm{~Hz}$. Five impedance sampling points were registered per frequency decade. The impedance data were analysed using ZView software version 3.1c http://www. scribner.com/programs/zv31c.exe (Copyright 1990-201, Scribner Associates Inc., NC, USA written by D. Johnson).

\section{Results and discussion}

Processing conditions for the films were determined by understanding the thermal behaviour of the organic-inorganic material. Fig. 1 shows thermograms $\left(25-900{ }^{\circ} \mathrm{C}\right)$ of the MAPTMS/TMOS/HAp hybrid as a function of HAp content. The temperature at which the heated samples undergo major

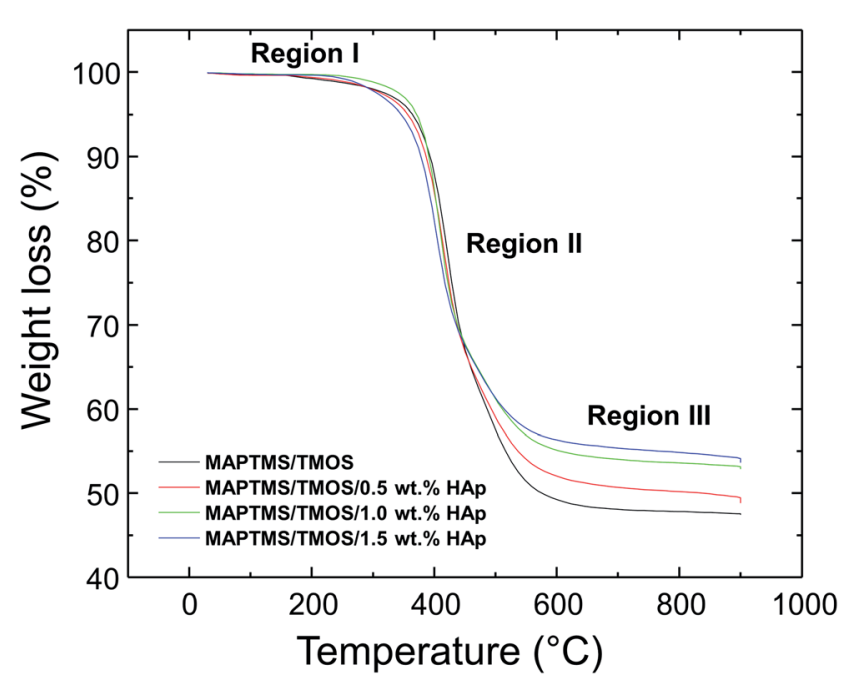

Fig. 1 Thermograms of the prepared MAPTMS/TMOS hybrids containing different amounts of HAp particles. 
conformational changes was determined from the mass loss profile. ${ }^{14}$

Thermograms showed three regions of mass loss. Region I is attributed to the elimination of condensation by-products, ethanol and water. ${ }^{15}$ Region II (above $350{ }^{\circ} \mathrm{C}$ ) is attributed to the partial thermal degradation of organic matter in the hybrids. Region III (350-500 ${ }^{\circ} \mathrm{C}$ ) is attributed to the complete burning of organics in the hybrid and water elimination from further silanol condensation. ${ }^{16}$ Small losses after $800{ }^{\circ} \mathrm{C}$ in all samples are attributed to further burning of the residual organics in the hybrid and $\mathrm{Si}-\mathrm{O}-\mathrm{Si} / \mathrm{Si}-\mathrm{O}-\mathrm{Me}$ condensation.

Structural characterisation of cured hybrid films was performed using ATR-FTIR spectroscopy. Fig. 2 shows ATR-FTIR spectra of the prepared coatings on Ti6Al4V substrates. The ATR-FTIR band assignments for these films are presented in Table 1. All hybrids present a characteristic band around 1015 $\mathrm{cm}^{-1}$ attributed to $\mathrm{Si}-\mathrm{O}-\mathrm{Si}$ stretching vibrations, associated with the structural backbone of the hybrid material. ${ }^{17}$ The band at $2957 \mathrm{~cm}^{-1}$ may be ascribed to $\mathrm{C}-\mathrm{H}$ stretching absorptions of the $\mathrm{CH}_{3}$ residues. ${ }^{18}$ The bands at $1447 \mathrm{~cm}^{-1}$ correspond to the symmetrical and asymmetrical $\mathrm{CH}_{3}$ deformational (umbrella) modes. ${ }^{19,20}$ The stretching vibration of the $\mathrm{C}=\mathrm{O}$ group at 1720 $\mathrm{cm}^{-1}$ is attributed to the carboxyl of acrylate. ${ }^{19}$ The existence of these residues after thermal treatment at $120{ }^{\circ} \mathrm{C} / 2 \mathrm{~h}$ indicates that these films still contained organic material. In the ATR

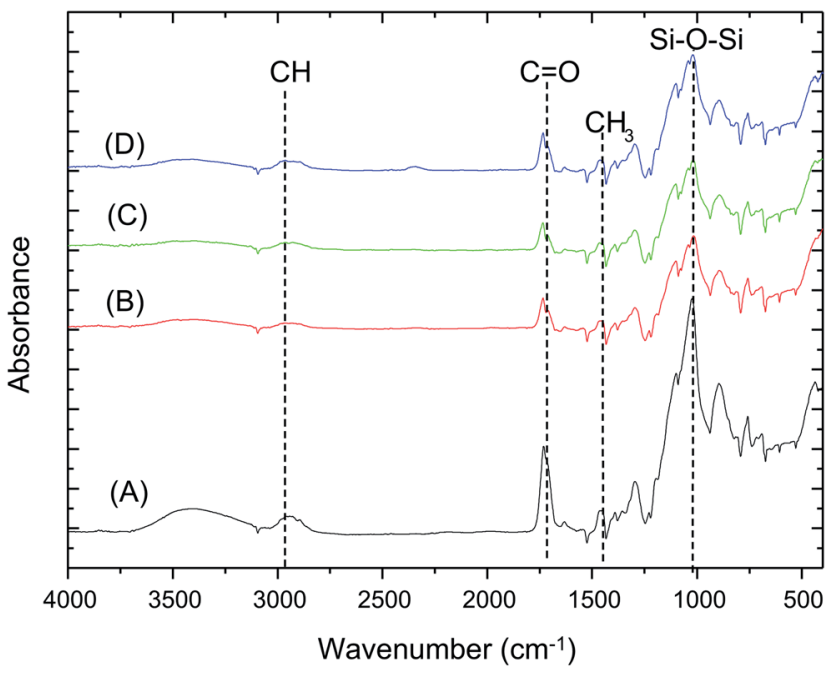

Fig. 2 Representative ATR-FTIR absorption spectra of MAPTMS/ TMOS/HAp-Ti6Al4V systems containing: 0 (A), 0.5 (B), 1 (C) and $1.5 \mathrm{wt} \%$ (D) HAp.

Table 1 Assignment of ATR-IR bands in MAPTMS/TMOS-Ti6AI4V systems

\begin{tabular}{lll}
\hline Wavenumber $\left(\mathrm{cm}^{-1}\right)$ & Assignment & References \\
\hline $3100-3600$ & $\nu \mathrm{O}-\mathrm{H}(\mathrm{Si}-\mathrm{OH}$ groups) & 18 \\
2957 & $\nu \mathrm{C}-\mathrm{H}(\mathrm{Si}-\mathrm{R}$ organic group) & 18 \\
& $\nu \mathrm{C}-\mathrm{H}\left(-\mathrm{OCH}_{2} \mathrm{CH}_{3}\right)$ & \\
1447 & $\delta \mathrm{CH}_{2}\left(\mathrm{Si}-\mathrm{R}^{2}\right.$ organic groups) & 19 and 20 \\
1720 & $\nu \mathrm{C}=\mathrm{O}$ (methacryloxy groups) & 19
\end{tabular}

spectra of the HAp containing hybrid [Fig. 2(B)-(D)], the absence of component bands $\left(1045 \mathrm{~cm}^{-1}\right)$ corresponding to $\mathrm{Si}-$ $\mathrm{O}-\mathrm{P}$ indicates no incorporation of phosphates into the silica sites of the lattice. These observations indicate that the dispersed HAp particles exist as an 'inert'material in the sol-gel matrix and do not form or bond with the siloxane network.

Solid-state ${ }^{29} \mathrm{Si},{ }^{13} \mathrm{C}$ and ${ }^{31} \mathrm{P}$ NMR were used to determine the nature of the condensed species present in the hybrid films after curing at $120{ }^{\circ} \mathrm{C}$ for $2 \mathrm{~h}$. Solid state ${ }^{29} \mathrm{Si}$-NMR spectroscopy was used to measure the degree of condensation (extent of reaction) in the hybrid films and gave information about the nature of the organosilica network and cross-linkage of the polysiloxane chains. ${ }^{21}$ In ${ }^{29} \mathrm{Si} \mathrm{NMR}$, peak assignments are described in terms of $\mathrm{T}$ units, assignable to $\mathrm{Si}$ atoms surrounded by one $\left(\mathrm{T}^{1}\right)$, two $\left(\mathrm{T}^{2}\right)$ or three $\left(\mathrm{T}^{3}\right)$ siloxane $(\mathrm{Si}-\mathrm{O}-\mathrm{Si})$ bonds, respectively. ${ }^{22}$

These $\mathrm{T}$ units have been used to measure the degree of condensation (extent of reaction) in the xerogels as a function of the HAp content. Four peaks for silica network units in the pure xerogel MAPTMS/TMOS (0 wt\% HAp) were observed at -59.6 ppm $\left(\mathrm{T}^{2}\right),-67.7 \mathrm{ppm}\left(\mathrm{T}^{3}\right),-100.41 \mathrm{ppm}\left(\mathrm{Q}^{3}\right)$ and, $-111.22 \mathrm{ppm}$ $\left(\mathrm{Q}^{4}\right)$, respectively [Fig. $\left.3 \mathrm{~A}(\mathrm{~A})\right]$. Signals, $\mathrm{Q}^{3}\left(\mathrm{SiOH}(\mathrm{OSi})_{3}\right)$ and signals $\mathrm{Q}^{4}\left(\mathrm{Si}(\mathrm{OSi})_{4}\right)$ corresponding to three and four hydroxyl groups that took part in condensation reactions, respectively. ${ }^{21}$ The MAPTMS monomer has a trialkoxysilane functionality at each end group and should form $\mathrm{T}^{3}$ species when fully condensed. TMOS has tetraalkoxysilane units and upon condensation should result in $\mathrm{Q}^{4}$ species. It was clear that the ${ }^{29} \mathrm{Si}-\mathrm{NMR}$ spectra of the xerogel control sample [Fig. 3A(A)] and the HAp containing xerogel [Fig. 3A(B and C)], contain T signals,
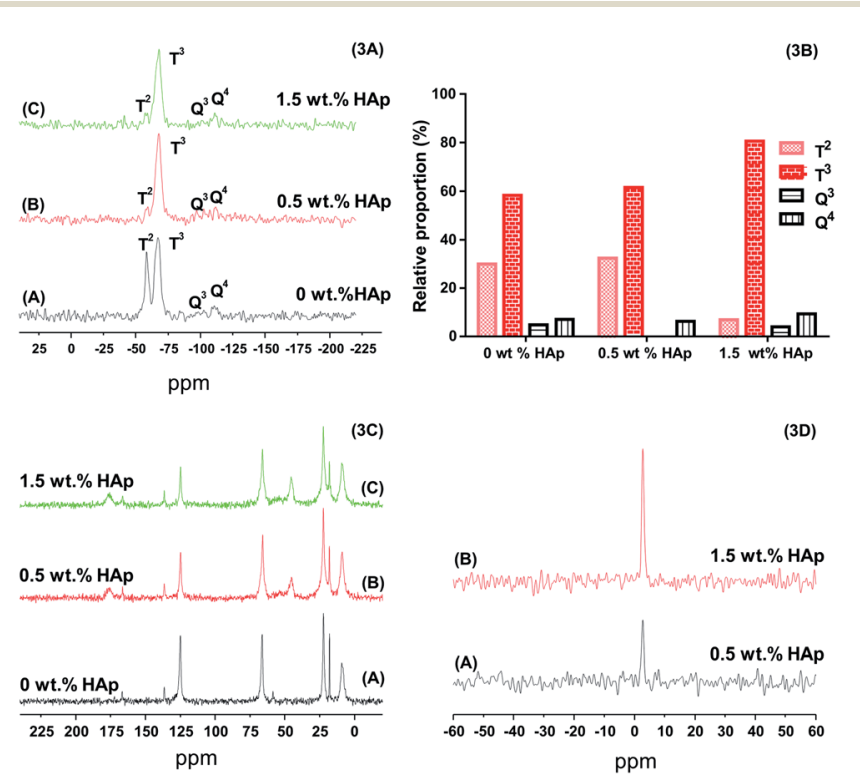

Fig. 3 Solid state ${ }^{29} \mathrm{Si}$ NMR spectra (3A) of MAPTMS/TMOS/HAp hybrids containing 0 (A), 0.5 (B) and $1.5 \mathrm{wt} \%$ (C) HAp. Relationship of the signals (3B), for species T2, T3, Q3, and Q4 in the MAPTMS/TMOS hybrid with differing HAp content. Solid state ${ }^{13} \mathrm{C}-\mathrm{NMR}$ spectra $(3 \mathrm{C})$ of MAPTMS/TMOS/HAp hybrids containing: 0 (A), 0.5 (B), and 1.5 wt\% (C) HAp. Solid state ${ }^{31} \mathrm{P}$ NMR spectra (3D) of MAPTMS/TMOS/HAp hybrid containing: 0 (A), 0.5 (B) and $1.5 \mathrm{wt} \%$ (C) HAp. 
due to the polymerisation of the MAPTMS precursor, that are more intense than the $\mathrm{Q}$ signals, associated with TMOS condensation. The $\mathrm{T}^{3}$ signal is more intense than that corresponding to $\mathrm{Si}$ in $\mathrm{T}^{2}$ environments indicating a high degree of cross-linking in the organopolysiloxane matrix. That is, the network is dominated by $\mathrm{T}^{3}$ building blocks, accompanied by minor amounts of $\mathrm{T}^{2}, \mathrm{Q}^{3}$ and $\mathrm{Q}^{4}$ units. The proportions of $\mathrm{T}$ and $\mathrm{Q}$ species in each xerogel system quoted in Fig. 3B and in Table 2 were obtained from deconvolution of the ${ }^{29} \mathrm{Si}$-NMR spectra.

Table 2 demonstrates that the addition of HAp leads to a higher degree of cross-linking in the organopolysiloxane matrix. The hybrid with HAp gave a larger fraction of $\mathrm{T}^{3}$ and $\mathrm{Q}^{4}$ than for the control sample. The relative intensity (in area) of $\mathrm{T}^{3} / \mathrm{T}^{2}$ signals is $1.94,9.96$, and 11.77 for xerogels containing $0,0.5$ and $1.5 \mathrm{wt} \%$ HAp respectively. These results indicate that the addition of the HAp accelerated the condensation reaction, i.e. increasing the cross-linking density and, therefore, increasing the amount of fully condensed $\mathrm{Si}-\mathrm{O}-\mathrm{Si}$ structures.

The patterns of the ${ }^{13} \mathrm{C}-\mathrm{NMR}$ peak positions were significantly more complex (Fig. $3 \mathrm{C}$ ). In the ${ }^{13} \mathrm{C}-\mathrm{NMR}$ spectrum of the MAPTMS/TMOS hybrids (0 wt\% HAp) [Fig. 3C(A)] signals were observed at $17.5 \mathrm{ppm}\left(\mathrm{C}-\mathrm{CH}_{3}\right), 59.34 \mathrm{ppm}\left(\mathrm{Si}-\mathrm{O}-\mathrm{CH}_{3}\right), 125.6$ ppm $\left(\mathrm{CH}_{2}=\mathrm{C}\right), 136.2 \mathrm{ppm}\left(\mathrm{CH}_{3}=\mathrm{C}\right), 166.2 \mathrm{ppm}\left(\mathrm{CH}_{3}=\mathrm{O}\right)$ of the methacryloxy group, $9.7 \mathrm{ppm}\left(\mathrm{Si}-\mathrm{CH}_{2}\right)$ and $23.6 \mathrm{ppm}$ $\left(\mathrm{Si}-\mathrm{CH}_{2} \mathrm{CH}_{2} \mathrm{CH}_{2}\right.$ ), appearing in all cases at similar chemical shift. ${ }^{22}$ The ${ }^{13} \mathrm{C}-\mathrm{NMR}$ spectra of the HAp containing xerogel [Fig. 3C(B and C)] showed an additional signal at $175.5 \mathrm{ppm}$.

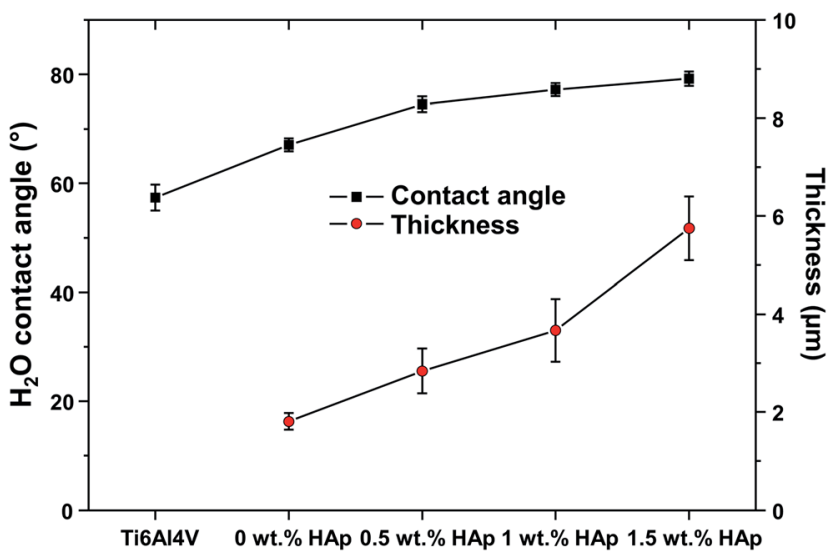

Fig. 4 Contact angle and thickness variation of MAPTMS/TMOS coatings deposited on Ti6Al4V for various amounts of HAp.

Table 2 Chemical shifts $\delta$ (ppm) and peak area (\%) of T and $Q$ units from deconvolution of 29Si NMR spectra

$\delta(\mathrm{ppm})$ and peak area $\%$

\begin{tabular}{lllrrrr}
\hline & $\mathrm{T}^{0}$ & $\mathrm{~T}^{1}$ & \multicolumn{1}{c}{$\mathrm{T}^{2}$} & $\mathrm{~T}^{3}$ & $\mathrm{Q}^{3}$ & \multicolumn{1}{c}{$\mathrm{Q}^{4}$} \\
\hline \multirow{2}{*}{$0 \mathrm{wt} \%$ HAp } & - & - & -58.63 & 66.97 & -100.41 & -111.22 \\
& - & - & 29.94 & 58.35 & 4.79 & 6.93 \\
$0.5 \mathrm{wt} \%$ HAp & - & - & -58.78 & -67.60 & - & 110.00 \\
& - & - & 6.17 & 61.49 & - & 32.34 \\
1.5 wt\% HAp & - & - & -57.90 & -67.83 & -101.91 & -111.01 \\
& - & - & 6.83 & 80.39 & 3.84 & 9.14
\end{tabular}

The weak signal at $175.5 \mathrm{ppm}$, is assignable to carbonate ions of the carbonate HAp used. ${ }^{23}$ The disappearance of the peak at $59.34 \mathrm{ppm}$ corresponding to $\left(\mathrm{Si}-\mathrm{O}-\mathrm{CH}_{3}\right)$, in the spectra of HAp containing hybrids indicated that HAp addition catalysed the hydrolysis and breakdown of this un-hydrolysed species to form condensed Si-O-Si units. This agrees with the results obtained from ${ }^{29} \mathrm{Si}$-NMR which showed enhancement of condensation after addition of HAp. ${ }^{31} \mathrm{P}-\mathrm{NMR}$ spectra of the MAPTMS/TMOS/ HAp xerogel [Fig. 3D(A and B)] possess only a single signal at 2.9 ppm characteristic of crystalline HAp. ${ }^{24}$

Wettability of metallic biomaterial surfaces is a key factor affecting not only protein adsorption and cell attachment but also corrosion in the body. The degree of wetting is described by the contact angle $(\theta)$, the angle at which the liquid-gas interface meets the solid-liquid interface. ${ }^{25}$ The surface wetting properties of the prepared hybrid films with and without HAp was characterised by contact angle measurement of $\mathrm{ddH}_{2} \mathrm{O}$ by the sessile drop method. The mean contact angles and standard deviation for each of the films is shown in Table 3 and Fig. 4.

The contact angles of the HAp containing films show wetting values lower than that of the control film without HAp. The contact angle results for the prepared films are $57.4 \pm 2.83^{\circ}$ for uncoated Ti6Al4V alloy, 67.1 $\pm 1.17^{\circ}$, for MAPTMS/TMOS without HAp and $74.5 \pm 1.44^{\circ}, 77.2 \pm 1.23^{\circ}$ and $79.2 \pm 1.30^{\circ}$ for MAPTMS/TMOS/HAp films contain $0.5,1$ and 1.5 wt\% HAp respectively. All measurements carried out show that the contact angle increases with HAp content. The contact angle relationships were as follows:

\section{MAPTMS/TMOS/HAp > MAPTMS/TMOS > uncoated Ti6Al4V}

This relationship can be related to the higher organic content of the silane hybrid and with the increase in cross-linking of the siloxane network as HAp was added. These results are in agreement with the ${ }^{29} \mathrm{Si}-\mathrm{NMR}$ results showing a decrease in the $\mathrm{T}^{2}$ species and an increase in the content of $\mathrm{T}^{3}$ species in the hybrids containing HAp. The surface should exhibit an optimum hydrophobicity to facilitate adsorption of the protein in its native form. The films prepared in this study are in the range of 67.1 to $79.2^{\circ}$. The reported optimum contact angle range being $60-80^{\circ}$, so an enhancement of protein adsorption over the Ti6Al4V alloy surface and improved biomaterial performance could be expected. ${ }^{26}$

The thickness of the films with and without HAp was measured using a stylus profile-meter, Fig. 4 and Table 3. The coating thickness increased as the content of HAp in the film increased.

Table 3 Contact angle and thickness of MAPTMS/TMOS coatings as a function of HAp content

\begin{tabular}{lcl} 
Surface & Contact angle $\theta \mathrm{H}_{2} \mathrm{O}\left({ }^{\circ}\right)$ & Thickness $(\mu \mathrm{m})$ \\
\hline Ti6Al4V & $57.4 \pm 2.83$ & - \\
MAPTMS/TMOS 0 wt\% HAp & $67.1 \pm 1.17$ & $1.80 \pm 0.168$ \\
MAPTMS/TMOS 0.5 wt\% HAp & $74.5 \pm 1.44$ & $2.84 \pm 0.457$ \\
MAPTMS/TMOS 1 wt\% HAp & $77.2 \pm 1.23$ & $3.67 \pm 0.639$ \\
MAPTMS/TMOS 1.5 wt\% HAp & $79.2 \pm 1.30$ & $5.74 \pm 0.655$
\end{tabular}


Fig. 5 shows EDXa and SEM micrographs of a Ti6Al4V substrate after coating, with and without HAp. Fig. 5(A) shows SEM micrographs of MAPTMS/TMOS coatings on Ti6Al4V, cured at $120{ }^{\circ} \mathrm{C}$ for $2 \mathrm{~h}$. SEM observations showed the formation of smooth, uniform and crack free protective films on the substrates that can be expected to lead to good corrosion resistance of Ti6Al4V alloys. The presence of the Ti in the EDXa spectra arises from detection of the underlying Ti6Al4V alloy, Fig. 5(E1).

Fig. 5(B1-B3) show micrographs of Ti6Al4V substrates coated with MAPTMS/TMOS/HAp. The HAp particles are well distributed over the surface, even at $1.5 \mathrm{wt} \%$ HAp content. The EDXa of HAp containing films indicated the presence of calcium, phosphorus, oxygen, silicon and carbon, Fig. 5(E2). No pore structures were observed in the size range of the HAp particles used and particles appeared to be entirely encapsulated by the sol-gel (comparison Fig. 5(B and D)).

The biocompatibility of the coated Ti6Al4V alloy which affects the biological response depends on the chemical composition of the surface and surface roughness. ${ }^{27}$ Thus, the roughness of the film is critical factor which affects the implant fixation period and fixation strength with body tissues. Confocal microscopy was used to study the surface of the prepared hybrid films, roughness parameters are summarized in Table 4.

From analysis of the MAPTMS/TMOS-Ti6Al4V system, a $R_{\mathrm{a}}$ surface roughness value of $0.162 \pm 0.038 \mu \mathrm{m}$ was obtained. The slight increase of the $R_{\mathrm{a}}$ roughness value when compared with the uncoated alloy $(0.094 \pm 0.018 \mu \mathrm{m})$ could be due to the evaporation of solvents during the curing step at $120^{\circ} \mathrm{C}$ for $2 \mathrm{~h}$. This process may result in the formation of small peaks and valleys where solvent evaporation took place.
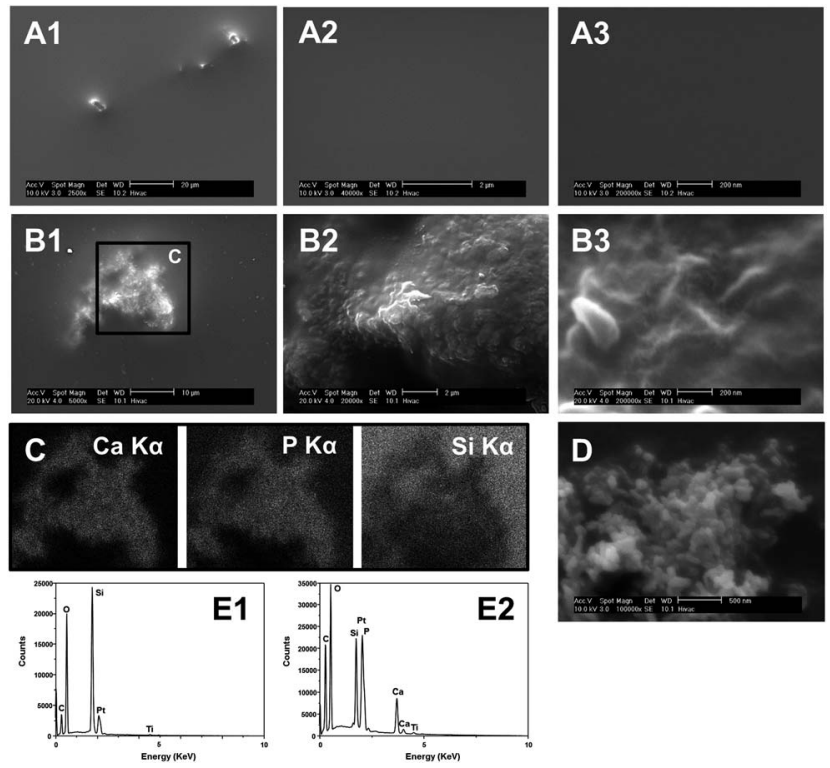

Fig. 5 SEM/EDXa micrographs for prepared hybrid coatings deposited on Ti6Al4V, including 0 wt\% (A) and 1.5 wt\% (B) HAp at different magnification (1-3). EDXa mapping (C) shows $\mathrm{Ca}$ and $\mathrm{P}$ localised to the encapsulated HAp. HAp alone is represented by micrograph (D). EDXa of films containing $0 \mathrm{wt} \%$ and $1.5 \mathrm{wt} \% \mathrm{HAp}$ are represented as E1 and E2 respectively.
Table 4 Surface roughness parameters for uncoated and hybrid coated (one layer) Ti6Al4V alloy

\begin{tabular}{llll}
\hline Surface & $R_{\mathrm{a}}(\mu \mathrm{m})$ & $R_{\mathrm{p}}(\mu \mathrm{m})$ & $R_{\mathrm{v}}(\mu \mathrm{m})$ \\
\hline Ti6Al4V & $0.094 \pm 0.018$ & $0.467 \pm 0.153$ & $-0.361 \pm 0.104$ \\
0 wt\% HAp & $0.162 \pm 0.038$ & $0.999 \pm 0.666$ & $-0.644 \pm 0.198$ \\
0.5 wt\% HAp & $0.163 \pm 0.028$ & $1.390 \pm 0.911$ & $-0.650 \pm 0.155$ \\
1 wt\% HAp & $0.165 \pm 0.012$ & $0.631 \pm 0.150$ & $-0.606 \pm 0.103$ \\
1.5 wt\% HAp & $0.275 \pm 0.073$ & $2.819 \pm 0.957$ & $-1.855 \pm 0.606$
\end{tabular}

Biomineralisation, protein adsorption, osteoblast cytotoxicity/ viability and cytoskeleton after culture on coated Ti6Al4V substrates

Surface bioactivity of the MAPTMS/TMOS/HAp hybrid coatings was assayed by immersing coated alloys in simulated body fluid (SBF) to determine by SEM/EDXa if precipitation of biomimetic HAp layers occurred. SEM/EDXa data of MAPTMS/TMOS and MAPTMS/TMOS/1.5 wt\% HAp coated alloys after 15 days immersion in SBF solution are shown in Fig. 6 . In both cases the surface became covered with precipitated material although this was more extensive for the sample initially containing $1.5 \%$ HAP (Fig. 6).

EDXa analysis of the exposed surfaces showed the presence of $\mathrm{Ca}$ and $\mathrm{P}$ in these precipitates. The EDXa spectra also exhibited peaks corresponding to $\mathrm{K}, \mathrm{Na}, \mathrm{Mg}$ and $\mathrm{Cl}$, all elements present in the SBF. The $\mathrm{Ca}$ and $\mathrm{P}$ present gave an atomic ratio of $0.45( \pm 0.23)$ and $0.58( \pm 0.36)$ respectively for coatings without and with HAp addition.

The mechanism of precipitate formation during immersion in SBF solution could be explained by the presence of silanol groups at the coating-solution interface, providing favourable nucleation sites for attracting calcium and phosphate ions from the SBF through electrostatic interactions and forming a precipitate layer on the surface. ${ }^{28}$ The enhanced formation of precipitates on films containing HAp particles, suggested that HAp incorporation in the films enhances biomineralisation.

The chemical composition of the implant surface strongly affects protein adsorption behaviour. ${ }^{7}$ This can be explained through interaction between functional groups on the film surface and those of the protein itself. The protein adsorption characteristics of the coatings was examined using fibrinogen, a

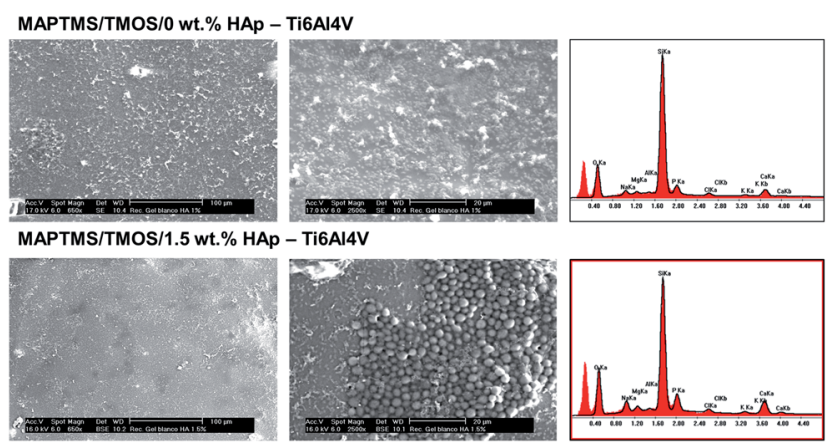

Fig. 6 SEM micrographs and EDXa spectra of MAPTMS/TMOS 0 and $1.5 \mathrm{wt} \%$ HAp, before and after immersion for 15 days in SBF. 
serum protein understood to replace serum albumin by the Vroman effect, implicated in biomaterial-host body responses and of interest in the bone regeneration process itself. ${ }^{29}$ After immersion of the coated surfaces in $1 \mathrm{mg} \mathrm{mL}^{-1}$ fibrinogen PBS solution, adsorption was measured after $1 \mathrm{~h}$ at $37{ }^{\circ} \mathrm{C}$, Fig. 7(A).

The amount of adsorbed fibrinogen onto the prepared hybrid films was $7.469 \pm 0.59$ and $10.06 \pm 0.59 \mu \mathrm{g} \mathrm{cm}^{-2}$ for the uncoated and silane coated alloy ( $0 \mathrm{wt} \% \mathrm{HAp}$ ) and $15.49 \pm 0.07$, $17.62 \pm 0.40 \mu \mathrm{g} \mathrm{cm}^{-2}$ for films containing 0.5 and $1.5 \mathrm{wt} \%$ HAp respectively, Fig. 7(A). Significantly more fibrinogen absorbed to the coated alloy and to the silane film with HAp.

The increase in fibrinogen adsorption to the surface of the MAPTMS/TMOS/HAp-Ti6Al4V systems was likely due to protein adsorption to HAp by an electrostatic interaction. ${ }^{31} \mathrm{Ca}^{2+}$ sites on HAp can absorb negatively charged proteins and $\mathrm{PO}_{4}{ }^{3-}$ sites can absorb positively charged proteins. ${ }^{30}$ Since the $\alpha$-C domains of fibrinogen are positively charged under the conditions used, fibrinogen would likely bind to the $\mathrm{PO}_{4}{ }^{3-}$ sites of the HAp surface by electrostatic forces. The existence of HAp in the deposited films helps such surfaces adsorb more fibrinogen relative to those without HAp.

Cell proliferation and attachment are fundamental processes of wound healing and integration of biomaterials with tissue. ${ }^{32}$ A preliminary investigation into the influence of

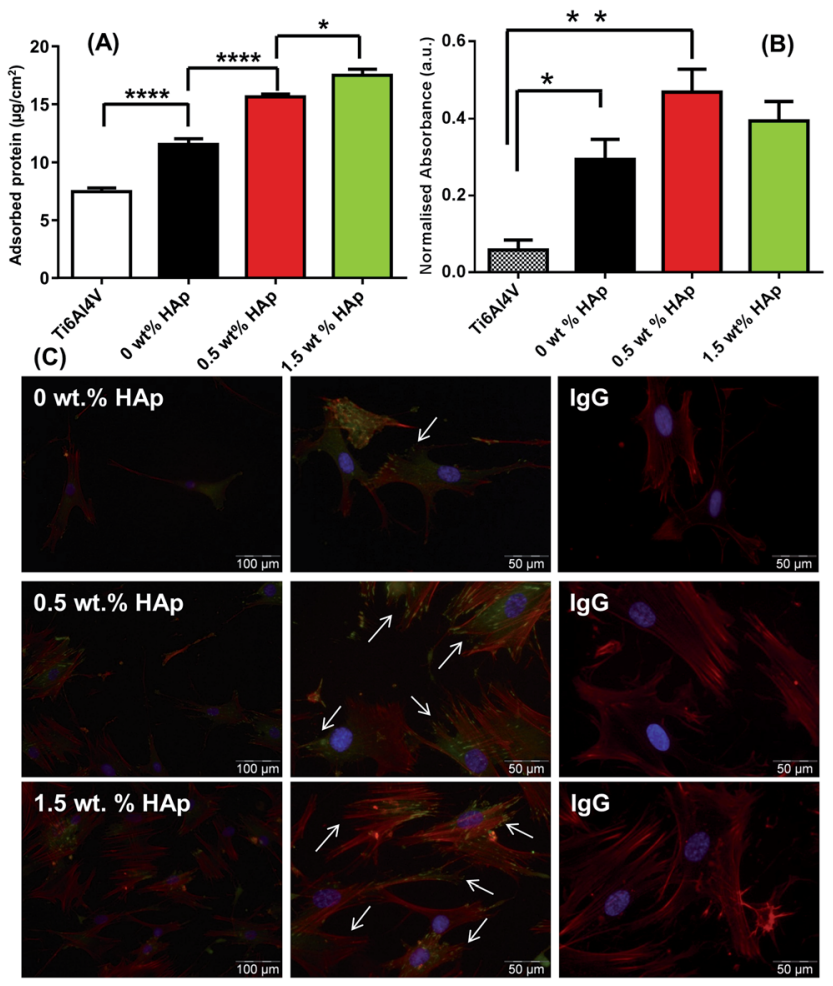

Fig. 7 Amount of fibrinogen adsorbed (A) on uncoated Ti6Al4V, MAPTMS/TMOS-Ti6AI4V and MAPTMS/TMOS/HAp-Ti6Al4V systems. Neutral red viability/cytotoxicity assay (B) for NHOst cultured on Ti6Al4V, MAPTMS/TMOS-Ti6AI4V and MAPTMS/TMOS/HAp-Ti6AI4V systems over seven days. Fluorescence micrographs (C) of NHOst cultured on MAPTMS/TMOS-Ti6AI4V and MAPTMS/TMOS/HApTi6Al4V surfaces. Vinculin: green, f-actin: red and, nuclei: blue, isotype controls are also represented. the different coatings on normal human osteoblasts (NHOst) viability/cytotoxicity was evaluated in vitro using the neutral red uptake assay based on dye uptake by living cells. ${ }^{33}$ In parallel experiments, the morphology of osteoblasts was characterised by immunofluorescence staining of the cell cytoskeleton to assess osteoblast adhesion.

Cell viability/cytotoxicity as assessed by the neutral red assay is shown in Fig. 7(B). The trend for NHOst cell viability was higher on MAPTMS/TMOS/HAp-Ti6Al4V with 0.5 and $1.5 \mathrm{wt} \%$ HAp, than on MAPTMS/TMOS-Ti6Al4V or uncoated Ti6Al4V systems. Osteoblast viability was lowest on the uncoated Ti6Al4V surface. That the toxicity of the uncoated alloy was higher with respect to the coated surfaces, could be due to ion dissolution which has been demonstrated to adversely affect the healing of bone. ${ }^{34} \mathrm{Ti6Al} 4 \mathrm{~V}$ is generally considered as a 'standard material' for orthopaedic and dental implant applications. On the other hand, vanadium is cytotoxic and can initiate adverse tissue reactions which may lead to the higher cell cytotoxicity observed. ${ }^{34}$ In comparison to the uncoated alloy and films without HAp, the MAPTMS/TMOS/HAp coated surfaces showed greater average cell viability, though results did not reach statistical significance versus the MAPTMS/TMOS surface. However the level of viability of NHOst on the hybrid films containing HAp was significantly higher than the MAPTMS/ TMOS surfaces without HAp in comparison to the Ti6Al4V alloy. These results suggest that modifying the sol with $0.5 \mathrm{wt} \%$ of bioactive HAp is sufficient to improve osteoblast viability, but greater additions did not result in further improvement.

Osteoblast adhesion is an important step in the acceptance of artificial implants by the living body and is a prerequisite for successful osteointegration of the implant in vivo. Adhesion to the implant surface can be divided into three sequential events: (a) cell attachment, (b) cell spreading and, (c) formation of focal adhesions and actin stress fibres. ${ }^{35}$ Focal contacts are formed at the leading edge of a migrating cell and may mature into focal adhesion plaques. Vinculin is one of several proteins involved in the formation of a focal adhesion plaque. ${ }^{36}$ Adhesion may be affected by surface composition and topology. The ability of an adherent cell to attach and spread on a substrate can in part be assessed by looking at the morphology of the cell and its cytoskeleton. To further understand the nature of the interactions of NHOst with the prepared films, the expression of vinculin and the organization of actin filaments were visualised by immunofluorescence (Fig. 7(C)).

Fewer cells were observed on the MAPTMS/TMOS-Ti6Al4V system, Fig. 7(C). Greater numbers of cells were observed for the MAPTMS/TMOS/HAp-Ti6Al4V systems, in this respect the immunofluorescence micrographs are in agreement with the cytotoxicity/viability assay performed. It was observed that osteoblasts on the coated substrates containing HAp showed greater spreading, more substantial networks of f-actin stress fibres and focal adhesion sites than cells growing on the coating without HAp, suggestive of better adhesion and integration between the osteoblasts and the surface.

Ultimately in vivo implantation of the coated alloys would be required to adequately assess the impact of HAp incorporation in the manner described on biocompatibility. However, that 
NHOst are not adversely affected in terms of viability or adhesion to the coatings, rather that HAp incorporation appears beneficial in these respects demonstrates the coatings viability for in vivo studies.

\section{In vitro corrosion protection behaviour studies}

In vitro corrosion and protection studies of the prepared coatings on the surface of Ti6Al4V were carried out using electrochemical impedance measurements. Fig. 8 shows the evolution of impedance plots (Nyquist representations) with the immersion time in SBF of a MAPTMS/TMOS/HAp-Ti6Al4V sample containing HAp $1 \mathrm{wt} \%$. Fig. 8(A) shows the Nyquist plots for the $10^{5}$ to $10^{-3} \mathrm{~Hz}$ frequencies range. Fig. 8(B) shows in detail the high frequency arcs.

The impedance data were analysed using ZView software, with good fitting obtained using the electrical equivalent circuit show in Fig. $9,{ }^{37}$ where $R_{\mathrm{S}}$ represents the electrolyte resistance. $C_{\text {coat }}$ is associated to the coating capacitance. $R_{\text {coat }}$ is related to the coating pore resistance. $R_{\text {corr }}$ and Cdl correspond to the corrosion resistance of the metal substrate and to the double layer capacitance at the metal-electrolyte interface respectively, both at the base of pores and damaged areas developed in the coating during immersion tests in the corrosive media (SBF). Finally, Wo is associated with finite-length diffusion processes with reflective boundary conditions. ${ }^{38}$ To take into account the intrinsic inhomogeneity of the coating and metal surface, the capacitors included in this equivalent circuit have been implemented by using Constant Phase Elements (CPEs). ${ }^{39}$

The high frequency arc is ascribed to the $R_{\text {coat }} / C_{\text {coat }}$ couple. The middle frequency arc is due to the $R_{\text {corr }} / \mathrm{Cdl}$ couple. Sometimes this middle region is disguised by an overlap due to the interaction between the $R_{\text {coat }} / \mathrm{Cg}$ and $R_{\text {corr }} / \mathrm{Cdl}$ couples. Measurements with standalone organic membranes have confirmed the relationship between the single arc appearing in the impedance diagrams during early stages of degradation of organic coatings based on the same formulation as those membranes. ${ }^{\mathbf{4 0 - 4 2}}$ After finding a satisfactory physical interpretation for the impedance plots, two main criteria have been used for estimating the quality of the fitting results by using the equivalent circuit proposed; firstly the lower chi-squared value, and secondly the lower estimated errors (in per cent) for all the
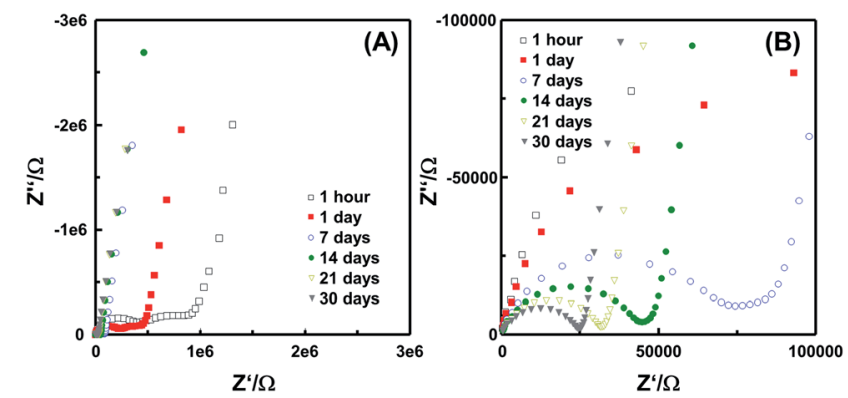

Fig. 8 Evolution with the immersion time of the Nyquist plots, represented in two different scales $[(A)$ and $(B)]$ obtained for the MAPTMS/ TMOS/HAp system deposited on Ti6Al4V surfaces for coating containing 1 wt\% HAp powder. electrical components of the equivalent circuit. ${ }^{43}$ The values obtained for each electrical element when the MAPTMS/TMOS/ HAp-Ti6Al4V system is tested after 1 day of immersion in SBF are shown in Table 5. This table shows that the calculation of errors for the electrical elements of the equivalent circuit give satisfactory results. The chi-square values (lower than $10^{-3}$ ) also show that the quality of the fitting results is appropriate.

The evolution plots with the immersion time of the $R_{\text {coat }}$, $C_{\text {coat }}$ equivalent circuit parameters for the coating containing 1 wt\% of HAp are shown in Fig. 10.

These plots show: (i) a continuous decrease of the ionic resistance of the coating pore $\left(R_{\text {coat }}\right)$ values with immersion time in SBF, (ii) a continuous increase of the parameter $C_{\text {coat }}-\mathrm{T}$, and (iii) an decrease of the parameter $C_{\text {coat }} \mathrm{P}$, respectively. This behaviour is typically associated with the loss of barrier properties and increase of water uptake in the coating with increasing immersion time. ${ }^{\mathbf{4 0 , 4 1}}$

The influence of the content of HAp on the impedance response of the coatings was measured after one day of immersion in SBF. Fig. 11(A and B) show Nyquist plots, represented in two different scales obtained for an uncoated Ti6Al4V sample and Ti6Al4V samples coated with MAPTMS/TMOS/HAp films containing different \% HAp: 0 (blank sample) 0.5, 1 and $1.5 \mathrm{wt} \%$ respectively. Fig. 11(A) shows the Nyquist plots for the $10^{5}-10^{-3} \mathrm{~Hz}$ frequency range. Fig. 11(B) shows a detail of the high frequency arcs. Table 6 shows the variations of resistance values $\left(\mathrm{R}_{\mathrm{HFA}}\right)$ and CPE parameters, $(\mathrm{CPE}-\mathrm{T})_{\mathrm{HFA}}$ and $(\mathrm{CPE}-\mathrm{P})_{\mathrm{HFA}}$, associated to the impedance responses at high frequencies as a function of HAp content. For the MAPTMS/TMOS/HAp-Ti6Al4V

Table 5 Values calculated with the Zview software for each of the elements of the equivalent circuit to analyse the MAPTMS/TMOS/HApTi6Al4V system. 1 wt\% HAp/silane content. Immersion time SBF: 1 day

\begin{tabular}{lllll}
\hline Element & Freedom & Value & Error & Error\% \\
\hline$R_{\mathrm{s}}$ & Free $( \pm)$ & 4.78 & $4.43 \times 10^{1}$ & $926 \times 10^{2}$ \\
$C_{\text {coat }}-\mathrm{T}$ & Free $( \pm)$ & $3.26 \times 10^{-9}$ & $1.80 \times 10^{-10}$ & 5.52 \\
$C_{\text {coat }}-\mathrm{P}$ & Free $( \pm)$ & 0.89 & $4.93 \times 10^{-3}$ & 0.55 \\
$R_{\text {coat }}$ & Free $( \pm)$ & $1.91 \times 10^{5}$ & $6.90 \times 10^{3}$ & 3.19 \\
Cdl-T & Free $( \pm)$ & $6.10 \times 10^{-7}$ & $1.11 \times 10^{-7}$ & 18.19 \\
Cdl-P & Free $( \pm)$ & 0.55 & $4.10 \times 10^{-2}$ & 7.44 \\
$R_{\text {corr }}$ & Free $( \pm)$ & $2.71 \times 10^{5}$ & $3.70 \times 10^{4}$ & 13.65 \\
Wo1-R & Free $( \pm)$ & $2.36 \times 10^{5}$ & $6.04 \times 10^{4}$ & 25.56 \\
Wo1-T & Free $( \pm)$ & 2.08 & $6.10 \times 10^{-1}$ & 29.50 \\
Wo1-P & Free $( \pm)$ & 0.47 & $1.2 \times 10^{-2}$ & 2.55 \\
Chi-squared & 0.0016699 & & &
\end{tabular}

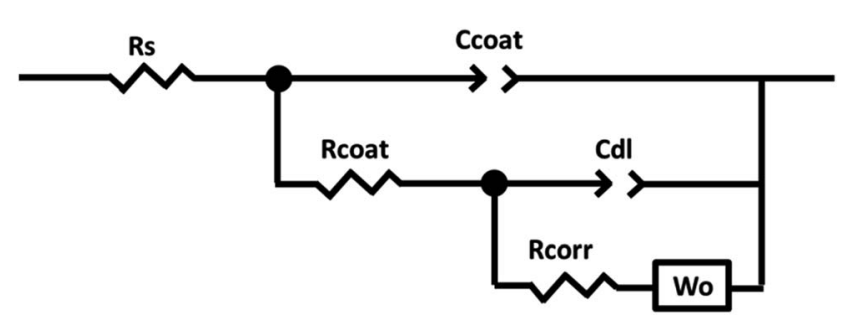

Fig. 9 Electrical equivalent circuits used to analyse the experimental electrochemical impedance data. 

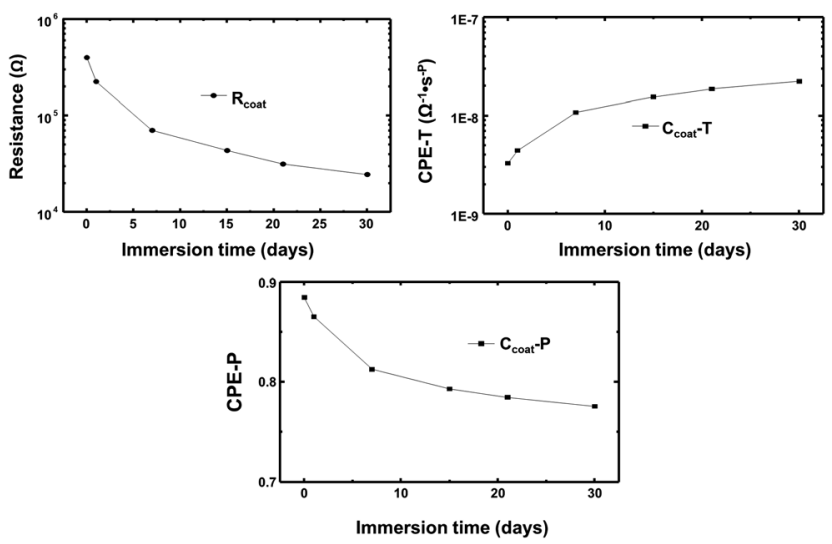

Fig. 10 Evolution of the equivalent circuit parameters associated to the HFA with the immersion time in Kokubo solution of the MAPTMS/ TMOS/HAp-Ti6Al4V system for a coatings containing 1 wt\% HAp powder.

systems, $\mathrm{R}_{\mathrm{HFA}}$ and $\mathrm{CPE}_{\mathrm{HFA}}$ are ascribed to the electrical properties of the sol-gel coating, $R_{\text {coat }}$ and $C_{\text {coat }}$ respectively (Fig. 11).

The CPE-T obtained from the high frequency arc (HFA) of the uncoated Ti6Al4V gives a value of $1.19 \times 10^{-5} \Omega^{-1} \mathrm{~s}^{-0.91}$ that corresponds with the typical order of magnitude of the electrochemical double layer capacitance of a bare metal in contact with an aqueous solution. In this case, the constant phase element, CPE simulates the non-ideal behaviour of the capacitor associated with the passive film formed on the Ti6Al4V uncoated surface, following the interpretation of Mansfeld and Wang et al., (1985), ${ }^{44}$ but implementing the ideal capacitor proposed by Mansfeld with a CPE in our case. In contrast with the results obtained for the uncoated Ti6Al4V alloy, the value of the CPE-T from the HFA for the MAPTMS/TMOS-Ti6Al4V system without HAp (blank sample) is two orders of magnitude lower than the CPEs found for the bare metal. This fact leads us to think that the physical meaning of this CPE is very different. Effectively, these values have the same order of magnitude of those typically expected for the capacitance of porous coatings of low thickness. The values calculated for the capacitance associated with the HFA of coatings based on sol-gel organicinorganic matrices modified with HAp are two orders of magnitude lower than those associated to the impedance HFA of the blank sample (i.e. $0 \mathrm{wt} \%$ HAp). These capacitances are usually associated with the dielectric properties of dense thin films with good barrier properties. So it can be concluded, that in this case, the resistance $\mathrm{R}_{\mathrm{HFA}}$ associated in parallel to this

Table 6 Resistance values and CPE parameters associated to the high frequency arc (HFA) obtained for an uncoated Ti6Al4V sample and for MAPTMS/TMOS/HAp-Ti6Al4V systems with different HAp content. Electrolyte: SBF. Immersion time: 1 day

\begin{tabular}{llll}
\hline Sample & $R_{\mathrm{HFA}} / \mathrm{ohms}$ & $\mathrm{CPE}_{\mathrm{HFA}}-\mathrm{T} / \Omega^{-1} \mathrm{~s}^{-\mathrm{P}}$ & $\mathrm{CPE}_{\mathrm{HFA}}-\mathrm{P}$ \\
\hline Uncoated Ti6Al4V & - & $1.19 \times 10^{-5}$ & 0.91 \\
0 wt\% HAp & $1.12 \times 10^{5}$ & $4.00 \times 10^{-7}$ & 0.82 \\
0.5 wt\% HAp & $6.86 \times 10^{5}$ & $1.29 \times 10^{-9}$ & 0.58 \\
1.0 wt\% HAp & $1.91 \times 10^{5}$ & $3.26 \times 10^{-9}$ & 0.89 \\
1.5 wt\% HAp & $1.87 \times 10^{5}$ & $2.46 \times 10^{-9}$ & 0.89
\end{tabular}
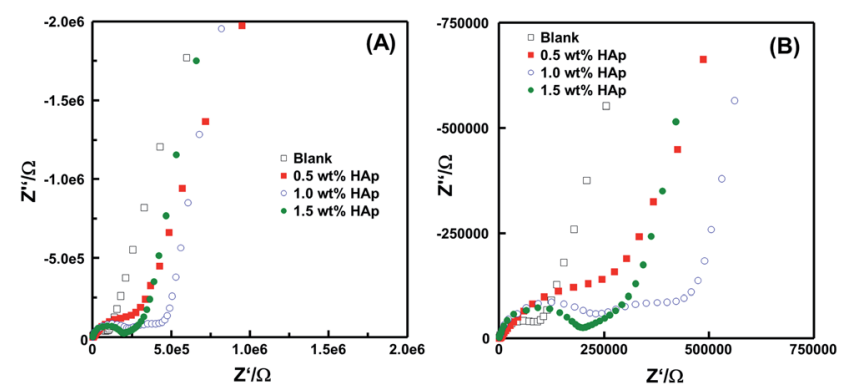

Fig. 11 Nyquist plots, represented in two different scales [(A) and (B)] obtained for an uncoated Ti6Al4V and Ti6Al4V samples coated with MAPTMS/TMOS/HAp films containing different HAp powder percentages: 0 (A), 0.5 (B), 1 (C) and 1.5 wt\% (D) HAp. Electrolyte: SBF. Immersion time: 1 day.

$\mathrm{CPE}_{\mathrm{HFA}}$ corresponds to the resistance of the electrolyte inside the pores of the coating. Consequently, the HFA of the metal/ coating systems are associated with two very important intrinsic electrical properties of the coating, $R_{\text {coat }}$ and $C_{\text {coat }}$.

\section{Conclusions}

Sol-gel derived MAPTMS/TMOS hybrids loaded with different HAp contents (0.5-1.5 wt\%) were successfully deposited onto Ti6Al4V alloys via a dipping technique, resulting in coatings with uniform and homogeneous particle distribution, without apparent defects. Hybrid films containing HAp particles exhibited higher thermal stability, greater thickness, and were of a more hydrophobic character than coatings without HAp. Solid-state multinuclear NMR and ATR-FTIR showed that after curing at $120^{\circ} \mathrm{C}$ for $2 \mathrm{~h}$ the cross linking in the prepared hybrid was enhanced by the addition of HAp.

The incorporation of the HAp particles in the hybrid network on the in vitro bioactivity increased fibrinogen adsorption as the content of HAp in the films increased. Cytotoxicity tests showed significant improvement for coated surfaces compared to the base alloy, though films containing increasing HAp showed smaller improvements in cell viability compared to the coating alone. Enhancement may be due to the efficiency of these coatings to act as effective physical barriers, inhibiting the release of toxic ions from the alloy to the culture medium. In terms of corrosion protection, impedance studies show that the corrosion protection performance of the MAPTMS/TMOS coatings was enhanced, probably due to the increased thickness and network reinforcement within the sol with hydroxyapatite powder addition rather than pore blocking. The best barrier properties were obtained for coatings containing 1 and $1.5 \mathrm{wt} \%$ HAp, which demonstrated greatest fibrinogen adsorption, osteoblast viability and adhesion. Incorporation of such quantities of HAp particles in hybrid sol-gel treatments would be considered a promising avenue for biomaterials development.

\section{Acknowledgements}

This work was supported by the Spanish Ministry of Economy and Competitivity (Project MAT2012-30854). A. A. El hadad 
acknowledges a pre-doctoral contract JAE financed by CSIC and the Interdisciplinary Biomedical Research Centre at NTU University. V. Barranco acknowledges a Ramon y Cajal researcher contract financed by CSIC-MINECO. GJH and CCP acknowledge support of the John van Geest Cancer Research Centre and RAE funding in support of work performed at NTU. Keith Dinsdale and Nicola Weston of the Advanced Materials Research Group at Nottingham University are thanked for providing access to their environmental SEM.

\section{Notes and references}

1 M. Geetha, A. K. Singh, R. Asokamani and A. K. Gogiac, Prog. Mater. Sci., 2009, 54, 397.

2 A. A. El hadad, V. Barranco, A. Jiménez-Morales, E. Peon and J. C. Galván, J. Phys.: Conf. Ser., 2010, 252, 012007.

3 O. Lev, Z. Wu, S. Bharathi, V. Glezer, A. Modestov, J. Gun, L. Rabinovich and S. Sampath, Chem. Mater., 1997, 9, 2354.

4 P. Gomez-Romero, Adv. Mater., 2001, 13, 163; B. M. Novak, Adv. Mater., 1993, 5, 422; C. Sanchez and F. Ribot, New J. Chem., 1994, 18, 1007.

5 P. Judeinstein and C. Sanchez, J. Mater. Chem., 1996, 6, 511; C. Sanchez, B. Julian, P. Belleville and M. Popall, J. Mater. Chem., 2005, 15, 3559; A. A. Letailleur, F. Ribot, C. Boissiere, J. Teisseire, E. Barthel, B. Desmazieres, N. Chemin and C. Sanchez, Chem. Mater., 2011, 23, 5082; C. Sanchez, P. Belleville, M. Popall and L. Nicole, Chem. Soc. Rev., 2011, 40, 696; C. Sanchez, K. J. Shea and S. Kitagawa, Chem. Soc. Rev., 2011, 40, 471.

6 Z. L. Dong, K. A. Khor, C. H. Quek, T. J. White and P. Cheang, Biomaterials, 2003, 24, 97; T. M. Sridhar, U. Kamachi Mudali and M. Subbaiyan, Corros. Sci., 2003, 45, 237; M. Marini, S. De Niederhausern, R. Iseppi, M. Bondi, C. Sabia, M. Toselli and F. Pilati, Biomacromolecules, 2007, 8, 1246; K. S. Raja, M. Misra and K. Paramguru, Mater. Lett., 2005, 59, 213; S. Jalota, S. Bhaduri, S. B. Bhaduri and A. C. Tas, J. Mater. Res., 2007, 22, 1593.

7 Y. Liu, D. Z. Sun, H. You and J. S. Chung, Appl. Surf. Sci., 2005, 246, 82; P. Roach, D. Farrar and C. C. Perry, J. Am. Chem. Soc., 2005, 127, 8168; P. Roach, D. Farrar and C. C. Perry, J. Am. Chem. Soc., 2006, 128, 3939.

8 A. Phanasgaonkar and V. S. Raja, Surf. Coat. Technol., 2009, 203, 2260.

9 W. J. van Ooij, D. Zhu, M. Stacy, A. Seth, T. Mugada, J. Gandhi and P. Puomi, Tsinghua Sci. Technol., 2005, 10, 639.

10 M. Quinet, B. Neveu, V. Moutarlier, P. Audebert and L. Ricq, Prog. Org. Coat., 2007, 58, 46.

11 I. Espigares, C. Elvira, J. F. Mano, B. Vazquez, J. San Roman and R. L. Reis, Biomaterials, 2003, 23, 1883; L. F. Boesel and R. L. Reis, Prog. Polym. Sci., 2008, 33, 180.

12 T. Kokubo, H. Kushitani, S. Sakka, T. Kitsugi and T. J. Yamamuro, J. Biomed. Mater. Res., 1990, 24, 721.

13 G. Repetto, A. del Peso and J. L. Zurita, Nat. Protoc., 2008, 3, 1125.

14 H. Y. Park, D. P. Kang, M. K. Na, H. W. Lee, H. H. Lee and D. S. Shin, J. Electroceram., 2009, 22, 309.
15 S. Yu, T. K. S. Wong, X. Hu and K. Pita, J. Electrochem. Soc., 2003, 150, F116.

16 C. B. Jing and J. X. Hou, J. Appl. Polym. Sci., 2007, 105, 697.

17 M. Pantoja, B. Díaz-Benito, F. Velasco, J. Abenojar and J. C. del Real, Appl. Surf. Sci., 2009, 255, 6386.

18 M. A. Rodríguez, M. J. Liso, F. Rubio, J. Rubio and J. L. Oteo, J. Mater. Sci., 1999, 34, 3867.

19 P. Innocenzi and G. Brusatin, J. Non-Cryst. Solids, 2004, 333, 137.

20 A. Franquet, H. Terryn and J. Vereecken, Appl. Surf. Sci., 2003, 211, 259.

21 A. Jiménez-Morales, J. C. Galván and P. Aranda, Electrochim. Acta, 2002, 47, 2281.

22 A. A. El hadad, D. Carbonell, V. Barranco, A. JiménezMorales, B. Casal and J. C. Galván, Colloid Polym. Sci., 2011, 289, 1875.

23 P. N. Gunawidjaja, A. Y. H. Lo, I. Izquierdo-Barba, A. García, D. Arcos, B. Stevensson, J. Grins, M. Vallet-Regí and M. Eden, J. Phys. Chem. C, 2010, 114, 19345.

24 L. H. Li, K. P. Kommareddy, C. Pilz, C. R. Zhou, P. Fratzl and I. Manjubala, Acta Biomater., 2010, 6, 2525.

25 D. Wang and G. P. Bierwagen, Prog. Org. Coat., 2009, 64, 327. 26 M. L. Pandey and S. K. Pattanayek, Appl. Surf. Sci., 2011, 257, 4731.

27 A. Aparicio, F. J. Gil, C. Fonseca, M. Barbosa and J. A. Planell, Biomaterials, 2003, 24, 263; A. W. E. Hodgson, Y. Mueller, D. Forster and S. Virtanen, Electrochim. Acta, 2002, 47, 1913. 28 L. Jonášová, F. A. Müller, H. Sieber and P. Greil, in Key Engineering Materials, 2004, vol. 254-256, pp. 1013-1016.

29 W.-J. Hu, J. W. Eaton and L. Tang, Blood, 2001, 98, 1231; S. G. Santos, M. Lamghari, C. R. Almeida, M. I. Oliveira, N. Neves, A. C. Ribeiro, J. N. Barbosa, R. Barros, J. Maciel, M. C. L. Martins, R. M. Goncalves and M. A. Barbosa, Acta Biomater., 2013, 9, 7209.

30 P. F. Cavanaugh, P. S. Moskwa, W. H. Donish, P. J. Pera, D. Richardson and A. P. Andrese, Invest. New Drugs, 1990, 8, 347.

31 K. M. Woo, J. Seo, R. Zhang and P. X. Ma, Biomaterials, 2007, 28, 2622.

32 K. E. Healy and P. Ducheyne, Biomaterials, 1992, 13, 553.

33 G. B. Sigal, M. Mrksich and G. M. Whitesides, J. Am. Chem. Soc., 1998, 120, 3464; P. Roach, D. Eglin, K. Rohde and C. C. Perry, J. Mater. Sci.: Mater. Med., 2007, 18, 1263; H. Niknejad, H. Peirovi, M. Jorjani, A. Ahmadiani, J. Ghanavi and A. M. Seifalian, Eur. Cells Mater., 2008, 15, 88; E. Borenfreund and J. A. Puerner, J. Tissue Cult. Methods, 1985, 9, 7.

34 D. J. Filman, R. J. Brawn and W. B. Dankler, J. Immunol. Methods, 1975, 6, 189.

35 M. Finnegan, Crit. Rev. Biocompat., 1989, 5, 1.

36 T. Albrektsson, P. I. Branemark, H. A. Hansson, B. Kasemo, K. Larsson, I. Lundstrom, D. H. McQeen and R. Salak, Ann. Biomed. Eng., 1983, 11, 1.

37 A. Jiménez-Morales, P. Aranda and J. C. Galván, J. Mater. Process. Technol., 2003, 143-144, 5.

38 C. Ho, I. D. Raistrick and R. A. Huggins, J. Electrochem. Soc., 1980, 127, 343; I. D. Raistrick, D. R. Franceschetti and 
J. R. Macdonald, Theory, Impedance Spectroscopy: Theory, in Experiment, and Applications, ed. E. Barsoukov and J. R. Macdonald, John Wiley \& Sons, Inc., USA, 2nd edn, 2005, 27, p. 149.

39 C. H. Hsu and F. Mansfeld, Corrosion, 2001, 57, 747; Y. Huang, H. Shih and F. Mansfeld, Werkst. Korros., 2010, 61, 302.

40 S. Feliu, J. C. Galván and M. Morcillo, Prog. Org. Coat., 1989, $17,143$.
41 S. Feliu, J. C. Galván and M. Morcillo, Corros. Sci., 1990, 30, 989.

42 P. Aranda, A. Jiménez-Morales, J. C. Galván, B. Casal and E. Ruiz-Hitzky, J. Mater. Chem., 1995, 5, 817.

43 M. C. Garcia-Alonso, L. Saldana, C. Alonso, V. Barranco, M. A. Munoz-Morris and M. L. Escudero, Acta Biomater., 2009, 5, 1374.

44 F. Mansfeld and Y. Wang, Mater. Sci. Eng., A, 1995, 198, 51. 